\title{
Comparison of the results of early and elective laparoscopic cholecystectomy in Oltu State Hospital: a retrospective 3-year study
}

\author{
Necip Altundaş \\ Department of General Surgery, T.C Ministry of Health Erzurum Oltu State Hospital, Erzurum, Turkey
}

\begin{abstract}
Introduction: The objective of this study was to present the experience of 1 center with early and elective laparoscopic cholecystectomy (LC), which can be performed in state hospitals but requires further specialized treatment when serious complications develop.

Materials and Methods: Cases of LC performed as an elective or an emergency procedure in a 100-bed county state hospital between June 2015 and February 2018 were retrospectively reviewed. Patient demographic characteristics; the presence of systemic disease; clinical, laboratory, and radiological findings; transition to open surgery; duration of hospital stay; and complications were analyzed.
\end{abstract}

Results: A total of 142 patients were included in the study, of which $115(80.9 \%)$ were female and $27(19.1 \%)$ were male. The mean age of the patients was 49.31 years (range: 17-75 years). LC was performed early in 35 patients $(24.6 \%)$ due to acute cholecystitis. The mean duration of surgery was 49.01 minutes (range: 30-120 minutes) for an elective LC, 86.6 minutes (range: 45-180 minutes) for an early LC, and 152 minutes (range: 120-185 minutes) for open surgery. The duration of hospitalization averaged 3.4 days (range: $2-10$ days) for elective patients and 4.6 days (range: $3-5$ days) for emergency cases. The duration of surgery and hospital stay were extended in patients who underwent early LC or open surgery compared with elective cases. The LC cases that were converted to open surgery included 5 acute cholecystitis patients $(14.2 \%)$ with difficult dissections and 1 in which the hepatocystic triangle could not be isolated. One elective LC $(0.9 \%)$ was also transitioned to open surgery due to hemorrhage. Intraoperative biliary injury was encountered in only 1 patient $(0.7 \%)$ who was subsequently referred to an advanced hospital center.

Conclusion: LC can be reliably performed in county state hospitals when there is adequate laparoscopic experience, knowledge, equipment, and assistant health personnel available. In cases of complications, directing those patients to more advanced centers where hepato- pancreato-biliary surgery is performed is thought to be beneficial regarding morbidity and mortality.

Keywords: Acute cholecystitis; hepato-pancreato-biliary; laparoscopic cholecystectomy. 


\section{Introduction}

Gallstones are present in 10\% of the adult population and are the most common ailment of the gallbladder and bile ducts. ${ }^{[1]}$ The incidence of gallstones increases with advancing age and is three times more common in women than men. ${ }^{[1,2]}$ Gallstones can become symptomatic with dyspeptic complaints, acute or chronic cholecystitis, or complications, such as inflammation, blockages, or cancer. ${ }^{[3]}$ LC has become the gold standard treatment worldwide in patients with symptomatic cholelithiasis and is accepted as the standard surgical treatment for acute cholecystitis, which accounts for $20 \%$ of bile duct diseases. ${ }^{[3,4]}$

LC has become the preferred choice over open cholecystectomy, due to the low postoperative pain, shortened duration of hospital stay, early mobilization, and good cosmetic results regarding aesthetics associated with the procedure. With advancements in surgical techniques and the increase in operator experience, some factors previously considered as contraindications for LC have disappeared..$^{[5]}$

We present the LC experiences and complications from our county state hospital and describe serious complications and those patients best treated in fully equipped surgical center hospitals by experienced surgeons.

\section{Materials and Methods}

Between June 2015 and February 2018, the cases of 142 patients who underwent elective and early LC in our 100-bed county state hospital were retrospectively reviewed. Ultrasonographic imaging had been performed to determine the presence of gallstones, along with other radiologic findings. Preoperatively, liver function tests (serum total/ direct bilirubin, alkaline phosphatase, lactate dehydrogenase, aspartate aminotransferase, alanine aminotransferase), C-reactive protein (CRP), and whole blood counts were evaluated. Acute cholecystitis cases were diagnosed with fever, Murphy positivity, CRP-WBC increase, thickening of the gallbladder wall, and pericholecystic fluid collection. All LC procedures were performed by a single general surgeon in our group $\mathrm{C}$ county state hospital. Two patients underwent three-port access procedures, and all others underwent pneumoperitoneum formation with standard four-port access and 10 to $14 \mathrm{mmHg}$ intraabdominal pressure. Cases were evaluated for age, gender, the presence of systemic disease, reasons for the transition to open surgery, duration of hospital stay, and complications.

\section{Statistical Analysis}

We used SPSS 23.0 (IBM, Armonk, NY, USA) analyze the variables. Suitability of normal distribution for the data is examined by using the Shapiro-Wilk test, and the variance homogeneity is assessed by using Levene's test. For comparing two independent groups based on quantitative data, we used the Mann-Whitney U test, which incorporates the results from Monte Carlo simulation. Quantitative variables are given as the average \pm standard error and the median change $(\mathrm{min} / \mathrm{max})$, whereas the categorical variables are presented as $\mathrm{n}(\%)$ in the tables. We studied the variables based on $95 \%$ confidence level at $\mathrm{p}<0.05$.

\section{Results}

A total of 142 patients operated between June 2015 and February 2018 were included in the study. Of these, 115 (80.9\%) were female, and 27 (19.1\%) were male. The female/male ratio was 4.2. The average age of women was 49.97 years (range: 17-75), and the average age of men was 49.11 years (range: $27-75$ ). The average age was 49.31 years. Hypertension was found in $16(11.2 \%)$, diabetes mellitus in $10(7 \%)$, and 4 patients (2\%) obesity (BMI: 3540) (Table 1). Elective LC was performed on 107 (75.4\%) patients, and 35 (24.6\%) were operated in the early period due to acute cholecystitis. Conversion of early LC for acute cholecystitis to open surgery occurred in five cases, including four (11.4\%) due to difficult dissection of the hepatocystic triangle and one (2.8\%) due to bile tract injury. In addition, one patient $(0.9 \%)$ who underwent elective LC was converted to open surgery due to hemorrhage $(\mathrm{p}<0.05)$ (Table 2).

Table 1. Socio-demographic characteristics of patients and additional diseases

\begin{tabular}{lc} 
Variables & $\begin{array}{c}\text { Study Group } \\
(\mathbf{n = 1 4 2 )}\end{array}$ \\
\hline $\begin{array}{l}\text { Age range (mean) } \\
\text { Gender (\%) } \\
\quad \text { Male }\end{array}$ & $49.31(17-75)$ \\
$\quad$ Female & $27(19.1)$ \\
Additional diseases (\%) & $115(80.9)$ \\
$\quad$ Diabetes mellitus & $10(7)$ \\
$\quad$ Hypertension & $16(11.2)$ \\
$\quad$ Obesity (BMI 35-40) & $4(2)$ \\
\hline BMI: Body mass index. &
\end{tabular}


Table 2. The rate of transition to open surgery due to complications

\begin{tabular}{lcccl} 
Procedures & $\begin{array}{c}\text { Total cases } \\
(\mathbf{n = 1 4 2 )}\end{array}$ & $\begin{array}{c}\text { Open surgery } \\
\text { transitions (\%) (n=6) }\end{array}$ & $\mathbf{p}$ & $\begin{array}{l}\text { Complications leading to open } \\
\text { surgery transitions }\end{array}$ \\
\hline $\begin{array}{l}\text { Elective laparoscopic } \\
\text { cholecystectomy }\end{array}$ & 107 & $1(0.94)$ & $<0.05$ & - Hemorrhage \\
$\begin{array}{l}\text { Early laparoscopic } \\
\text { cholecystectomy }\end{array}$ & 35 & $5(14.3)$ & & $\begin{array}{l}\text { - Dissection difficulty (4 cases) } \\
\text { - Intraoperative biliary tract injury } \\
(1 \text { case) }\end{array}$
\end{tabular}

Table 3. Surgical treatment and hospitalization time

\begin{tabular}{lccc} 
& $\begin{array}{c}\text { Elective laparoscopic } \\
\text { cholecystectomy }\end{array}$ & $\begin{array}{c}\text { Early laparoscopic } \\
\text { cholecystectomy }\end{array}$ & p \\
\hline Total cases $(\mathrm{n}=142)$ & 107 & 35 & $<0.05$ \\
Surgery duration minutes (range) & $67.6(30-180)$ & $83.3(45-185)$ & $<0.05$ \\
Total hospitalization days (range) & $3.34(2-7)$ & $4.37(3-10)$ & \\
\hline
\end{tabular}

Patients with acute cholecystitis and early LC had a longer mean duration of surgery (83.3 min; range: 45-185) than those with LC under elective conditions (67.6 min; range: 30-180) $(\mathrm{p}<0.05)$. The mean hospitalization duration for acute cholecystitis and early LC cases was longer (4.37 days; range: 3-10) compared to elective LC cases (3.34 days; range: $2-7)(\mathrm{p}<0.05)$. Operation duration and mean hospitalization duration were both extended in LC cases, due to acute cholecystitis $(\mathrm{p}<0.05)$ (Table 3 ).

\section{Discussion}

Described by Philippe Mouret, a French gynecologist in 1987, LC is easily performed and has received great interest and acceptance among general surgeons, due to the associated low postoperative pain, shortened hospitalization time, early mobilization, and good cosmetic results. ${ }^{[6,7]}$ There has been much debate over the advantages of LC versus open cholecystectomy, with LC emerging as the preferred method. ${ }^{[7]}$ Since June 2015, we have been performing LC operations routinely for symptomatic gallstones and acute cholecystitis at our 100-bed county state hospital, completing $142 \mathrm{LC}$ operations in the last 2.5 years.

Gallstones are very rare in the pediatric population, increase in frequency with advancing age, and peak in those aged 40-60. In our study, the mean age was 49.1 years, which was compatible with the literature. It is also reported that gallstones are present two to four times more often in women than men. ${ }^{[1,2]}$ Similarly, in our study, 115 (80.9\%) patients with gallstones were women, and 27 (19.1\%) were men.

Some publications report that laparoscopic surgery was contraindicated for acute cholecystitis in the years when LC was first introduced and experience was lacking. ${ }^{[6]}$ Today, LC can be safely applied by experienced and welltrained surgeons and is no longer contraindicated for acute cholecystitis in $20 \%$ of biliary diseases. ${ }^{[8]}$ However, in acute cholecystitis, the rate of open cholecystectomy is evidently higher than in elective cases. It is documented that between $6 \%$ and $35 \%$ of acute cholecystitis cases of LC are converted to open surgery. ${ }^{[8,9]}$ The most common cause adhesions in patients who converted to open operations in Calot triangle is identified as acute cholecystitis and bleeding. ${ }^{[10]}$ The most important reasons for the high rate of open surgery transitions in acute cholecystitis cases are difficulty of dissection due to adhesions caused by inflammation and fibrosis around the sac and inadequate isolation of the anatomical structures. Bile duct injuries and hemorrhage are other causes for switching to open surgery. Another factor that increases the conversion to open surgery is past upper abdominal surgeries. Similar to the rate stated in the literature, $14.2 \%$ (5 patients) of the acute cholecystitis cases in our study, converted to open surgery, due to difficulty of dissection resulting from adhesions and difficulty in isolating the anatomical struc- 
tures. ${ }^{[10]}$ The most common causes of hemorrhage are intraoperative injuries and anatomical variations of vessels. ${ }^{[11]}$ One case of elective LC surgery (0.9\%) was converted to open surgery due to hemorrhage.

Mortality in LC, is the same as that in open cholecystectomy and is reported to be $0.0-0.9 \%{ }^{[12]}$ Mortality is often associated with concomitant diseases or intraperitoneal organ injuries resulting in peritonitis. There is no mortality in our series. In cases converted to open surgery in older age, mortality and morbidity is increased. ${ }^{[13]}$ For this reason, elective LC without acute cholecystitis is recommended for elderly patients with symptomatic biliary stone disease. ${ }^{[14]}$

Major vascular injury, which has a rate of $0.11 \%$ to $0.14 \%$ in the literature was not seen in our study. ${ }^{[15,16]}$ Operation duration, hospitalization time, mortality, and morbidity are increased in LC cases, due to acute cholecystitis and open surgery. ${ }^{[9,17]}$ In our study, the duration of the operation and the length of the hospital stay were also extended in such cases $(p<0.05)$. However, the reasons for the extended durations in our study in comparison to the literature were the difficulty of accessing the hospital from surrounding counties and villages, the inability to perform postoperative care in favorable conditions, and the relatively longer hospitalization desired by the patients following surgery.

The timing of LC is important in patients with acute cholecystitis. Some publications recommend early LC in the acute phase or elective LC after medical treatment in the late period. ${ }^{[18,19]}$ The dissection in LC cases performed during the acute phase is relatively simpler because inflammation and fibrosis are not yet fully developed and the anatomy can be isolated more easily. However, more careful dissection should be performed in early planned LC cases, due to the hydropic nature of the gallbladder, increase of bile duct wall thickness, fragile tissue, and increased risk of bleeding. It has been suggested that for some cases, the contents of the sac should be emptied to facilitate dissection and isolation of the anatomy. Some studies recommend early LC in the first $72 \mathrm{~h}$ while some extend this period up to $96 \mathrm{~h} \cdot{ }^{[9,18]}$ In our hospital, we performed early LC in cases where the disease was determined within 72 hand we prefer to perform elective LC after 6 to 8 weeks of medical treatment.

Bile duct injuries are one of the most frightening complications of cholecystectomy surgeries. While this complication reportedly occurred at a rate of $0.1 \%$ to $0.2 \%$ when open cholecystectomies were performed, the risk of biliary tract injuries increased to $0.8-1.4 \%$ in the years when LC began to be preferred. Over the years, however, with the increase of laparoscopic experience and knowledge, the incidence of biliary tract injury has declined to $0.5-0.6 \%$. ${ }^{[20]}$ Bile tract injuries that are noticed during surgery can be treated with different surgical techniques. ${ }^{[2]}$ The type of bile tract injury and the presence of experienced surgeons are factors that influence the success of the treatment. ${ }^{[21]}$ According to the Strasberg classification, surgical hepatico-jejunostomy is recommended for type E2 or full-layer bile duct injuries closer than $20 \mathrm{~mm}$ to the bifurcation in the common bile duct. ${ }^{[21,22]}$ This repair should be performed by an experienced hepatobiliary surgeon. If there is no hepatobiliary surgeon present, the patient should be transported to a center with sufficient experience in this area, by first providing drainage without performing any surgical procedure. ${ }^{[20]}$ The presence of vascular injuries associated with biliary injury should also be investigated. ${ }^{[22]}$ In our study, bile duct injury was observed in only one case $(0.7 \%)$ during surgery, and biliary tract repair was subsequently performed by a hepato-pancreato-biliary surgery unit at an advanced center.

LC is now the standard surgical treatment for symptomatic bile gallstones. This procedure can be reliably performed in county state hospitals where there is adequate laparoscopic experience, knowledge, equipment, and assistant health personnel available. One of the factors that affect the success frequency of LC is acute cholecystitis. The rate of open surgery and complications increase, and the duration of operation and hospitalization is prolonged, especially when LC is performed after the first 72 h. In instances of complications, directing those cases to more advanced centers where hepato-pancreato-biliary surgery is routine is thought to be more beneficial regarding morbidity and mortality.

\section{Disclosures}

Peer-review: Externally peer-reviewed.

Conflict of Interest: None declared.

\section{References}

1. Barbara L, Sama C, Morselli Labate AM, Taroni F, Rusticali AG, Festi $D$, et al. A population study on the prevalence of gallstone disease: the Sirmione Study. Hepatology 1987;7:913-7.

2. Sood S, Winn T, Ibrahim S, Gobindram A, Arumugam AA, Razali NC, et al. Natural history of asymptomatic gallstones: 
differential behaviour in male and female subjects. Med $\mathrm{J}$ Malaysia 2015;70:341-5.

3. Sharp KW. Acute cholecystitis. Surg Clin North Am 1988;68:269-79. [CrossRef]

4. Soper NJ, Stockmann PT, Dunnegan DL, Ashley SW. Laparoscopic cholecystectomy. The new 'gold standard'? Arch Surg 1992;127:917-21. [CrossRef]

5. Schirmer BD, Edge SB, Dix J, Hyser MJ, Hanks JB, Jones RS. Laparoscopic cholecystectomy. Treatment of choice for symptomatic cholelithiasis. Ann Surg 1991;213:665-76.

6. A prospective analysis of 1518 laparoscopic cholecystectomies. The Southern Surgeons Club. N Eng J Med 1991;324:1073-8. [CrossRef]

7. Troidl H, Spangenberger W, Langen R, al-Jaziri A, Eypasch $E$, Neugebauer $E$, et al. Laparoscopic cholecystectomy: technical performance, safety and patient's benefit. Endoscopy 1992;24:252-61. [CrossRef]

8. Glavic Z, Begic L, Simlesa D, Rukavina A. Treatment of acute cholecystitis. A comparison of open vs laparoscopic cholecystectomy. Surg Endosc 2001;15:398-401.

9. Pessaux P, Tuech JJ, Rouge C, Duplessis R, Cervi C, Arnaud JP. Laparoscopic cholecystectomy in acute cholecystitis. A prospective comparative study in patients with acute vs. chronic cholecystitis. Surg Endosc 2000;14:358-61. [CrossRef]

10. Kaushik R, Sharma R, Batra R, Yadav TD, Attri AK, Kaushik SP. Laparoscopic cholecystectomy: an Indian experience of 1233 cases. J Laparoendosc Adv Surg Tech A 2002;12:21-5.

11. Shurkalin BK, Kriger AG, Gorskiǐ VA, Ovanesian ER, Andreǐstev IL, Rzhebaev KE. Complications of laparascopic cholecystectomy. Vestn Khir Im I I Grek 2001;160:78-83.

12. Fried GM, Barkun JS, Sigman HH, Joseph L, Clas D, Garzon $\mathrm{J}$, et al. Factors determining conversion to laparotomy in patients undergoing laparoscopic cholecystectomy. Am J Surg 1994;167:35-41. [CrossRef]

13. Liu CL, Fan ST, Lai EC, Lo CM, Chu KM. Factors affecting con- version of laparoscopic cholecystectomy to open surgery. Arch Surg 1996;131:98-101. [CrossRef]

14. Nielsen LB, Harboe KM, Bardram L. Cholecystectomy for the elderly: no hesitation for otherwise healthy patients. Surg Endosc 2014;28:171-7. [CrossRef]

15. Usal H, Sayad P, Hayek N, Hallak A, Huie F, Ferzli G. Major vascular injuries during laparoscopic cholecystectomy. An institutional review of experience with 2589 procedures and literature review. Surg Endosc 1998;12:960-2. [CrossRef]

16. Geers J, Holden C. Major vascular injury as a complication of laparoscopic surgery: a report of three cases and review of the literature. Am J Surg 1996;62:377-9.

17. Brodsky A, Matter I, Sabo E, Cohen A, Abrahamson J, Eldar S. Laparoscopic cholecystectomy for acute cholecystitis: can the need for conversion and the probability of complications be predicted? A prospective study. Surg Endosc 2000;14:755-60. [CrossRef]

18. Bhattacharya D, Senapati PS, Hurle R, Ammori BJ. Urgent versus interval laparoscopic cholecystectomy for acute cholecystitis: a comparative study. J Hepatobiliary Pancreat Surg 2002;9:538-42. [CrossRef]

19. Uchiyama K, Onishi $H$, Tani M, Kinoshita H, Ueno M, Yamaue $\mathrm{H}$. Timing of laparoscopic cholecystectomy for acute cholecystitis with cholecystolithiasis. Hepatogastroenterology 2004;51:346-8.

20. Karvonen J, Gullichsen R, Laine S, Salminen P, Grönroos JM. Bile duct injuries during laparoscopic cholecystectomy: primary and long-term results from a single institution. Surg Endosc 2007;21:1069-73. [CrossRef]

21. McPartland $\mathrm{KJ}$, Pomposelli JJ. latrogenic biliary injuries: Classification, identification, and management. Surg Clin N Am 2008;88:1329-43. [CrossRef]

22. Strasberg SM, Hertl M, Soper NJ. An analysis of the problem of biliary injury during laparoscopic cholecystectomy. J Am Coll Surg 1995;180:101-25. 